\title{
On Problems with Descriptivism: Psychological Assumptions and Empirical Evidence
}

\author{
EDUARDO GARCÍA-RAMÍREZ AND MARILYN SHATZ
}

\begin{abstract}
We offer an empirical assessment of description theories of proper names. We examine empirical evidence on lexical and cognitive development, memory, and aphasia, to see whether it supports Descriptivism. We show that description theories demand much more, in terms of psychological assumptions, than what the data suggest; hence, they lack empirical support. We argue that this problem undermines their success as philosophical theories for proper names in natural languages. We conclude by presenting and defending a preliminary alternative account of reference from a developmental perspective.
\end{abstract}

\section{Background}

There is an ongoing philosophical debate with respect to the meaning and reference of proper names. There are three different kinds of theories: Millian, Descriptivist, and Hybrid. ${ }^{1}$

Millian theories claim that the only meaning of a proper name is its referent (see Mill, 1864). The view is usually complemented with a causal theory of reference (see Kripke, 1980; Evans, 1973). On this view, all a subject needs to understand a given name is to stand in the proper causal relation or have the proper referential intentions. Frege (1892) argues against this view and claims that names have both reference (Bedeutung) and sense (Sinn). Frege's 'sense' is commonly taken as an analogue of a definite description (but see Dummett, 1973, 1981); i.e. an expression like 'The F' where 'F' denotes a uniquely identifying property (or a set of properties that are together uniquely identifying), a property or set of properties that one and only one object has. According to Frege (1892), this descriptive mechanism fixes the reference and determines the meaning of any given name. To put it somehow, names have two different levels of meaning, the referent and the associated description. Since Mill and Frege, a great variety of Millian and

The authors would like to thank anonymous reviewers of an earlier version for their comments. The first author was supported by a research grant from the Mexican Council for Science and Technology (CONACyT).

Address for correspondence: Eduardo García-Ramírez, Instituto de Investigaciones Filosóficas, Universidad Nacional Autónoma de México, Cto. Mario de la Cueva S/N, Ciudad Universitaria, Coyoacan, C.P. 04510, México D.F., México.

Email: espurea@gmail.com

1 Hybrid Theories claim that some descriptive information is necessary for reference-fixing purposes but not for meaning-determination purposes. We do not discuss these theories anywhere in this paper. 
Descriptivist theories have been offered (see Braun, 2007; Lycan, 2006, for details). We will focus on Descriptivist theories.

Unlike the Millian view, Descriptivist theories require the speaker to represent or understand the relevant concepts expressed by the appropriate description. Millians, especially Kripke (1980), have argued against this view on the grounds that it demands more than is needed to understand a name. It is our contention that this claim is confirmed by the experimental data.

We want to clarify our argument. What does it mean to say that competent subjects know or understand something? ${ }^{2}$ Following various description theorists, we argue (see Section 5.1) that description theories are concerned with actual language use and, hence, that they should be complemented with empirical research. On this view, a proper account of names is an account of how names function in natural language. Thus, actual use of proper names is important both qua explanans as well as qua explanandum. Like Segal (2001), we believe that empirical research provides an adequate framework for semantic theorizing to proceed, although we recognize that there are different kinds of evidence and various ways to interpret them (see Section 5.4). With this in mind we use the term 'competent' simply to refer to any subject who is able to understand a proper name for referential purposes in a successful manner (i.e. she must be able to identify the referent of the relevant use of the name).

The issue is not whether description theories entail a psychological account; we take that as a given. Rather, the issue is whether they do it in an empirically supported way. To address this, we do several things. First, for a theory to be testable against psychological data, its theses must have operative analogues. Accordingly, in Section 2 we offer an operative account of description theories by assigning psychological analogues to descriptivist theses, and we restate their claims in psychological terms. Then, in Section 3, we present three kinds of data (lexical, cognitive, and memory) supporting a psychology that is incompatible with this characterization. We draw the philosophical implications for description theories in Section 4. The remaining sections address objections and sketch an alternative, more psychologically sound, account.

\section{What Descriptivism Presupposes}

There are three distinguishable kinds of description theories of proper names and several different versions of each, for a total of seven (see Table 1). These kinds

\footnotetext{
2 A popular answer in philosophy (see Wittgenstein, 1953; Austin, 1962) is that linguistic competence is a matter of language use or knowledge-how. Another option is to take competence as an instance of propositional knowledge, knowledge-that, which need not involve any actual use. This is still an open debate in philosophy. Generally speaking, linguists subscribe to the competence/performance distinction, thereby opening the door for a useindependent notion of competence. The distinction, however, is not widely accepted among philosophers. See Section 5 for further discussion.
} 


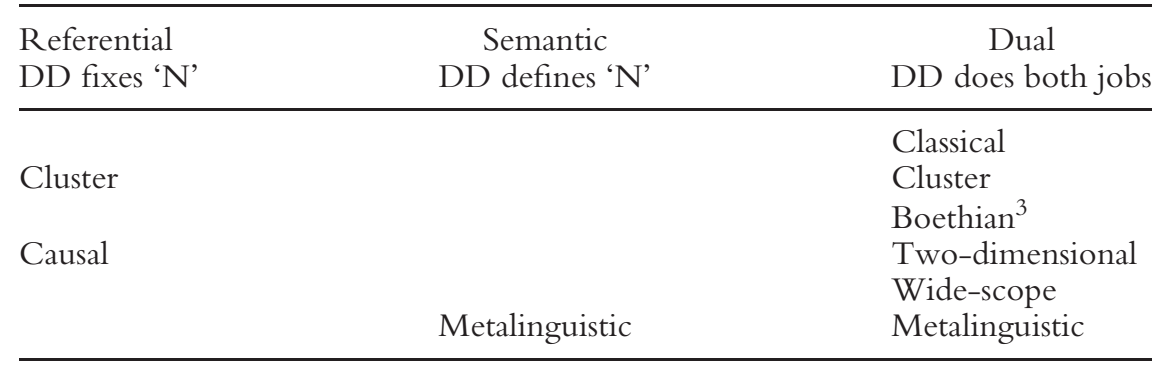

Table 1 Varieties of description theories of proper names.

vary depending on the job they take the relevant descriptions to do. They are what we dub 'referential', 'semantic' and 'dual' descriptivism. The differences among the particular versions of each kind, which depend on the properties they take the relevant descriptions to denote (e.g. causal, essential, disjunctive), are irrelevant for our purposes.

Referential descriptivist theories take a given definite description only to constitute the reference-fixing mechanism of the relevant name (e.g. Searle, 1983; Lewis, 1984; Jackson, 1998a). For semantic descriptivist theories the relevant definite description only determines the meaning of the name but does not fix its reference (e.g. Bach, 1981; Fodor, 1987; Geurts, 1997; Matushansky, 2008). Finally, Dual descriptivism takes definite descriptions to do both jobs: Fix reference and determine meaning (e.g. Russell, 1905; Strawson, 1959; Plantinga, 1978; Dummett, 1981; Stanley, 1997).

From a philosophical point of view, it may seem difficult to classify so many different versions of description theories, sometimes varying substantially from author to author, within the same category. Nevertheless, there is something they are all supposed to have in common. At the very least, as Machery, Mallon, Nichols and Stich (2004) claim, they all take competent speakers to 'associate a description with every proper name' (p. B1) In this section, we present the common claims underlying all forms of Descriptivism, as well as those common to some of them, and assign them psychological counterparts in order to answer a central question: What is required for the claim(s) to be fulfilled?

\subsection{Towards an Operative Account of Descriptivism}

We need an operative account of description theories to be able to test them against empirical data. We offer such an account in terms of relations of reference and semantics to cognition and memory. Description theories appeal to psychological

3 According to Plantinga (1978), Boethianism is the view that a proper name refers to a single essential property of its referent, a property that its referent and only its referent has. For example, it is Plato's essence to Platonize, thus, on this view 'Plato' refers to/means 'the one that platonizes'. 
(or internal) facts to account for referential uses of proper names. Referential theories are committed to REFERENTIAL, semantic ones to SEMANTIC, and dual ones to both.

REFERENTIAL for any competent subject $S$, any name ' $N$ ' and some appropriate definite description 'DD', S competently understands ' $N$ ' iff S refers to N by means of DD.

SEMANTIC for any competent subject $\mathrm{S}$, any name ' $\mathrm{N}$ ' and some appropriate definite description 'DD', S competently understands ' $N$ ' iff S understands DD and DD is the content of ' $N$ ' for S. ${ }^{4}$

What must psychologically be the case for REFERENTIAL and SEMANTIC to be true? Let us start with what description theorists have to say. According to Stanley:

If the descriptive picture is true, then for each expression in our language, we possess a priori uniquely identifying knowledge about its referent. Such a premise is more than just a useful tool in epistemological and metaphysical theorizing. For if the descriptive picture is true, then we have a rich store of a priori knowledge (1997, p. 565). ${ }^{5}$

We think it is fair to rephrase this as follows. According to description theories, competent speakers have a rich store of concepts or representations that they use to identify referents. These concepts are meant to be the cognitive correlates of the central linguistic tool, definite descriptions. (From now on, we will loosely talk about definite descriptions and, alternatively, uniquely identifying concepts to mean pretty much the same.) Our central claim is that description theorists demand too much in terms of cognitive skills. To make it hardest for us to support our claim, we will assume that the description theorists' position on concepts is the least demanding one; i.e. they view concepts as abilities (see Margolis and Laurence, 1999, for more on concepts as abilities). Then if our claim is supported, description theorists will be in fault even if their concept ontology is more demanding. Now, as Machery et al. (2004) put it, description theories claim that an object must 'uniquely or best satisfy the description associated' with the name in order to be its referent (p. B2). Hence, the Descriptivist's central claim is that to competently understand a name is at least partly to be able to identify objects by assessing their unique properties (i.e. properties that that object, and only that one, has). Notice that this

4 These two claims together illustrate the classical view of concepts as applied to proper names. See Margolis and Laurence, 1999, especially pp. 21-23.

5 Stanley does not explicitly say what he means by 'a priori knowledge'. One way to understand this, a paradigmatic example perhaps, is the kind of knowledge that can be obtained by simply knowing the meaning of a term. This seems to be what Stanley refers to by 'a priori knowledge', in other words, the knowledge that we have in virtue of the fact that we are competent speakers of a language. What is relevant here is not the account of the a priori, but the claim that speakers have a rich store of conceptual knowledge simply in virtue of their linguistic competence. 
claim applies to all referential, semantic, and dual versions since they demand the use of such knowledge either to fix reference or to determine meaning. This gives us a psychological analogue of Referential. We call it 'COgNitive'.

COGNITIVE for any competent subject $S$, any name ' $N$ ', and the relevant definite description 'DD', S competently understands ' $N$ ' only if $\mathrm{S}$ is able to identify $\mathrm{N}$ as having the unique properties denoted by 'DD'.

We claim that the evidence in Section 3 is incompatible with this picture. The studies reviewed in 3.1 show that competent understanding of names starts at about 6 months of age although property assessment in general is not in the repertoire of such young infants (see 3.2). It follows that to competently understand a name one need not be able to identify objects by assessing their unique properties. Section 3.3 shows that this separation between object identification and property assessment, as relates to proper names, is not altered by development. Even adults, who have greater linguistic and conceptual expertise, give evidence of such a split.

There is more to the Descriptivist picture. Semantic and dual versions also claim, first, that for each name there is something more than just its referent (i.e. names have 'content'); and second, that this so-called 'meaning of a name' is determined by a definite description that defines the name. These are strong claims. They presuppose the existence of a semantic content for names beyond reference (i.e. that of a relevant definite description), and that this content 'just is' the content of the name. Thus, these theories assume that accessing content is the same for both names and descriptions. This presupposes a particular information-processing model according to which the contents of names (if any) and descriptions have the same standing with respect to storage and retrieval. In particular, if I am unable to retrieve and use the appropriate description - perhaps owed to some peculiar case of aphasia - then I should also be unable to competently use the relevant proper name. This now gives us another psychological requirement that is the analogue of SEMANTIC. We call it 'MEMORY'.

Memory for any competent subject S, any name ' $N$ ' and some appropriate definite description 'DD', S cannot competently use ' $N$ ' without retrieving the content of 'DD'.

In Section 3.3 we present evidence of a double dissociation of proper names, suggesting that their storage and retrieval differs from the rest of the lexicon. In the relevant cases, speakers were able to recall the name and to use it to refer to the appropriate individual. We also present studies on how non-injured participants store and retrieve names, showing that names are more difficult to recall than common nouns. This suggests that storing and retrieving a name is not tantamount to storing and retrieving a definite description and thus, that the contents (if any) of names are not identical to those of descriptions. It must be, then, that the claims of semantic and dual description theorists are mistaken (see Table 2). 


\subsection{A Caveat}

We want to prevent confusion about metalinguistic descriptivism. There are two versions of it. On Kripke's (1980) version, any given name ' $N$ ' is associated with the description 'the referent of ' $N$ '. Those who defend the theory offer a different description: i.e. 'the bearer of ' $N$ '. These descriptions denote two different properties. An object can be the referent of a speaker's use of ' $N$ ' without thereby being named ' $N$ ' (or bearing the name ' $N$ '). Whether an object is a referent of ' $N$ ' depends on how a speaker uses ' $N$ '; whether it bears the name ' $N$ ' depends on social naming practices. As Geurts puts it, 'bearing a name is like bearing a tie. Like ties, names are seldom unique, but circumstances permitting they may be used for referential purposes [...]. Taken on its own [...] a name doesn't refer any more than a tie does' (Geurts, 1997, p. 326).

Consequently, a speaker need not know which name has been given to an object (which name it bears) in order to know it is the referent of her use of, say, ' $N$ '. All she needs to do is take the relevant object to be the referent of the name. On Kripke's version, metalinguistic descriptivism is trivially true. What we have to say here does not go against this theory. It does, however, speak against the less trivial version according to which speakers must understand that objects can be given names that they bear.

\section{The Evidence}

Here we review studies on lexical and cognitive development and on name retrieval. Our goal is to offer a picture of the lexical, cognitive and memory skills employed by subjects that understand proper names competently.

\subsection{Early Lexical Development}

Studies on early lexical development have shown that proper names are among the earliest words in an infant's lexicon and that this is so even though the early lexicon is very limited (see Nelson, 1973, 1974; Tardiff, Fletcher, Liang, Zhan, Kaciroti and Marchman, 2008).

Mandel, Jusczyk and Pisoni (1995) have shown that 4.5-month-olds detect the sound patterns of their own names and distinguish them from similarly stressed words. Jusczyk and Mandel-Emer (1997) investigated experimentally how accurate

Cognitive Memory

$S$ is able to identify objects by assessing their properties. Referential/Semantic/Dual $S$ cannot competently use $N$ without retrieving $D D$.

Semantic/Dual

Table 2 Speakers according to description theories. 
infants' representations are. Their first study suggests that 4.5-month-olds 'do not false alarm to an item that differs from their own names by a single phonetic feature' and 'that infants have a rather detailed representation of the sound patterns of their names' (pp. 14-15). A second study showed that the results were not just a consequence of the high frequency of 'name' sound patterns. Another study found that 6-month-olds respond preferentially to socially relevant sound patterns beyond their names (e.g. 'baby'), but not to other relevant words (e.g. 'mommy'). This suggests that 4.5 to 6 -month-old infants have some understanding of what their names refer to.

There is some controversy over how far 6-month-olds' referential ability extends. In a study using a different paradigm and presenting infants with more information (visual as well as auditory) than in the Jusczyk and Mandel-Emer study, Tincoff and Jusczyk (1999) found that 6-month-olds could associate pictures of their parents appropriately with the words 'mommy' and 'daddy'. They argue that 6-month-olds understand words like 'mommy' and 'daddy' and that they 'do not associate these words with men and women in general' (Tincoff and Jusczyk, 1999, p. 172). In another study, Jusczyk and Aslin (1995) showed that 6-month-olds could not detect familiar words such as 'dog' and 'cup' in fluent speech (although 7.5-month-olds could) whereas the work reported above (Jusczyk and Mandel-Emer, 1997) showed that they could detect their own names. Whether 6-month-olds understand other proper names besides there own may be at issue, but those proper names are treated differently from common nouns even at so young an age.

There is also some controversy over the nature of the infants' representations. Based on their work, Hallé and Boysson-Bardies (1996) argue that 11-montholds have a flexible, segmentally underspecified, yet lexical representation of familiar words. This contrasts with Stager and Werker (1997) who argue for a non-lexical account of infants as simply matching the input to familiar stored sound patterns. However, a non-lexical account does not explain why infants showed more detection ability when 'engaged in recognizing words rather than merely attending to meaningless speech sounds' (Hallé and Boysson-Bardies, 1996, p. 463). This evidence supports the view that young infants have an underspecified lexicon, rather than simply lacking one. Such a view seems more in line with the evidence presented above on 6-month-olds' understanding of at least their own names.

These data support our claim that young infants have a competent understanding of names. At 6 months of age, infants show comprehension of their names, and very likely of other words that are used as proper names referring to other socially relevant individuals. This early comprehension may be lexical or even prelinguistic, as it doesn't seem to be accompanied by either extensive lexical specification or grammatical understanding. This early ability develops within just a few months to include representations of less salient but very familiar words (e.g. 'dog' and 'cup') that by 9 months of age seem to function as kind terms (see Section 3.2). The evidence suggests, then, that proper names are the very first lexical items that young infants represent and understand in what very well may be a lexical 
way. The contrast with other kinds of names may initially be owed to the salience and emotional relevance of their own (and their parents') names. In any case, by 6 months, infants' own names appear to be special, specifically represented, accompanied by an understanding of reference and thus, competently understood as singular terms rather than as kind labels. We agree, then, with Hall (2009), who argues that from early on infants distinguish between proper and common nouns by distinguishing between proper-nameable (e.g. persons) and other objects (e.g. inanimate objects), but we go even further by suggesting that proper nouns are primary. ${ }^{6}$

The primacy of proper name learning followed by kind-term understanding accords well with claims for a noun bias in word learning. This view holds that names do not demand the same cognitive skills as verbs and adjectives; ${ }^{7}$ hence, they are learned earlier. Nouns require the mapping of sounds onto non-linguistic contexts, making them easier to learn than verbs, which require more linguistic information. Proper nouns might be easiest of all because they require the least amount of mapping: The same sounds get mapped into the same unique context; i.e. the referent. The view also suggests an important developmental difference between names and adjectives, an understanding of which may appear at 14 months, while 'a robust link between adjectives and properties does not emerge until sometime after 18 months of age' (Booth and Waxman, 2009, p.20).

\subsection{Cognitive Development}

Referential, semantic and dual description theories assume that competent subjects must understand uniquely identifying properties either to fix the referent of a name ' $N$ ' or to understand its meaning (see Section 2.1). We have argued that 4.5 to 6-month-olds understand names. In this section, we offer evidence suggesting that 6-month-olds do not have the cognitive ability to use unique properties to identify (i.e. fix) the referent or to determine the meaning of the names they understand in terms of those properties. Because there is no direct evidence beyond what we have already presented on 6-month-olds, our argument is inferential as follows: 1) It is implausible that one could use property information to identify objects unless one understood (or possessed) property concepts; 2) only at 9 months of age do infants show a glimmer of understanding property concepts (Xu, 2002),

6 It is possible with this evidence that infants understand their own names as a proper name version of a kind label, a label of a kind with one single instance. But, as far as we know, there is no evidence of this being the case. Furthermore, evidence in Section 3.2, suggests that the sort of descriptive property information that young infants understand is not enough to meet Descriptivist demands. It is not uniquely identifying descriptive information.

7 Data from both children and adults suggest that nouns are easier to learn than verbs (e.g. Gentner, 1982; Snedeker and Gleitman, 2004), with cross-linguistic evidence mitigating the noun-ease phenomenon (e.g. Choi and Gopnik, 1993; Tardif, Shatz and Naigles, 1997; Snedeker, Li and Yuan, 2003). 
perhaps as a consequence of an initial or preliminary understanding of kind terms (see Section 3.1); 3) it is likely that the use of property information (if needed) is similar for both proper names and kind terms, i.e. both depend on having property concepts; 4) therefore, if there is no ability to understand or use properties before 9 months of age, the understanding of proper names by 6 months of age cannot depend on property descriptions.

$\mathrm{Xu}$ and colleagues (see $\mathrm{Xu}$ and Carey, 1996; Xu, Carey and Quint, 2004) argue for the psychological independence of object individuation from property assessment in early infancy. They assume the results of Spelke, Breilinger, Macomber and Jacobson (1992) suggesting that an object concept is genetically encoded and test the object-first hypothesis (see Bower, 1974) according to which infants may use 'spatiotemporal criteria for individuating and tracing identity of objects well before they can use other property information' (Xu and Carey, 1996, p.114). They presented 10-month-olds with events in which an object (e.g. a rabbit) emerged from behind a screen alternating with a second object (e.g. a cup) emerging from the other side of the screen. Infants were presented with expected (two different objects) and unexpected (a single object) outcomes. If infants were able to identify objects by assessing their properties (e.g. shape), they should have looked longer at the unexpected outcome.

The experiment included property, spatiotemporal, and baseline conditions; the last showed that infants had an intrinsic preference (i.e. looked longer) for two objects. Successful trials required the infants to overcome this preference. Infants did overcome the baseline in the spatiotemporal but not in the property condition. This suggests that 10-month-olds do have a concept of BOUNDED PHYSICAL OBJECT but no proper understanding of more specific property concepts, e.g. SHAPE.

A second, comparative study showed that 12-month-olds can overcome the baseline preference in the property trial. Xu and Carey hypothesize that this change may be developmental and related to the learning of common nouns between 10 and 12 months of age. The suggested developmental trajectory portrays property assessment as an ability that appears not at 6 months of age but much later. In these studies, the experimenters did not use linguistic aids (e.g. words like 'dog' and 'truck'), thereby excluding the possibility that the results are owed to a lack of understanding of kind terms.

In a different study, $\mathrm{Xu}$ (2002) found that nine-month-olds were able to form a representation of two different objects when they were presented with different labels, e.g. 'Look, a duck!' and 'Look, a ball!' This suggests that early understanding of property concepts is tied to an understanding of kind terms. Since early understanding of kind terms follows that of proper names (see Section 3.1), there is no reason to grant property understanding for proper names to 6-month-olds.

Moreover, the claim to relatively late understanding of property concepts is supported in a more recent study by Xu et al. (2004). They presented 12-montholds with two different objects that differed in color but not in shape (e.g. a red and a green ball). The 12-month-olds were unable to represent them as distinct objects, suggesting that infants at that age have a limited understanding of general notions, 
e.g. PHYSICAL OBJECT, SHAPE, but not uniquely identifying ones such as color (see $\mathrm{Xu}$ et al., 2004, p. 159). Thus, although it can be argued that 12-month-olds, and even 9-month-olds, do have some understanding of properties, it does not seem to be adequate to support Descriptivist claims. ${ }^{8}$

The data in 3.1 and 3.2 suggest the following developmental trajectory. First, at around 4.5 to 6 months, proper nouns give infants the idea that specific familiar phonological strings are used for social communication to designate spatiotemporally individuated objects (e.g. referent of ' $N$ '). Between 6 and 9 months, infants begin to recognize, however, that some familiar strings get used for more than one, in some way similar, individual. Hence, at around 9 months, the idea of common noun as a kind term emerges. At around 10 to 12 months of age, properties start to be used to discriminate kinds, possibly as infants look for ways to discriminate kind differences beyond the labels. The process of creating an arsenal of specific property concepts useful in definite descriptions goes on considerably past 12 months of age. Smith (1984) studied 2-, 3- and 4-year-olds' understanding of attributes or properties (i.e. being red) and distinctions between kinds of attributes (e.g. between being red and being big). Her results show that 2-year-olds understand attributes but not distinctions between kinds of attributes (see also Booth and Waxman, 2009).

In sum, in order to identify an object by assessing its unique properties, infants need an understanding of properties that develops over the second year of life. Even more, an initial understanding of general properties ( 9 months) takes place long after infants show an understanding of reference and proper names (4.5 to 6 months). Thus, understanding unique properties is not a necessary requirement for either reference fixing or understanding of proper names. Cognitively speaking, much less is required.

\subsection{Memory for Proper Names}

The suggested separation of proper name understanding from property assessment is confirmed by studies on memory. Because most of these are with adults, they also suggest that this separation is sustained throughout development. Furthermore, they offer an empirical basis from which to argue particularly against semantic and dual description theories (see Section 2).

Adults are able to use definite descriptions for reference fixing. Before Neptune could be seen, Le Verrier hypothesized that something perturbed the orbit of

\footnotetext{
8 Notice that even if we take the relevant descriptions to denote any property such as to include non-kind properties (e.g. spatiotemporal, shape, or color), it will not be enough for Descriptivist purposes. Descriptivism requires 'definite descriptions' that denote 'uniquely identifying properties' or a set of properties that are, together, uniquely identifying. Spatiotemporal, shape, and color properties do not seem to constitute such a 'uniquely identifying' set of properties. $\mathrm{Xu}$ et al. (2004) present evidence that 12-month-olds fail to distinguish (and thus to single out) two different objects that differ in color but not in shape.
} 
Uranus. 'Neptune' could not be taken to refer to any salient object; it was introduced as referring to 'the object that perturbed the orbit of Uranus'. Such anecdotes suggest that adults, at least, do reference fix with descriptions. The question now concerns the processing of names in adults. Is there evidence of distinctiveness of proper names in adult processing as there is in infants? Does the processing system change between infancy and adulthood such that definite descriptions are required in adult use of proper names? Or do adults simply have more options to use more information when called for? The empirical evidence suggests that adult use of proper names is more elaborated than that of infants but still relies on a basic distinctiveness of proper names in the processing system.

Broadly speaking, two kinds of neuropsychological studies prove the distinctiveness of proper name processing. First, some studies address how brain injuries affect proper name processing (i.e. anomia). (See Semenza, 2009, for an exhaustive review.) There are four observed varieties of proper name anomia: 1) damaged access to lexical level with intact semantic system; 2) damaged semantic system; 3) isolation of individual semantics; and, 4) damage to face processing. Lucchelli and De Renzi, (1992) and Semenza and Zettin (1989) present patients who were unable to retrieve names of people but could offer 'spontaneous definitions of the target' (Semenza, 2009, p. 354). Miceli et al., (2000) report a patient with selective damage for proper names but not comparable damage for common nouns. The patient was 'clearly impaired in all tasks that require full conceptual information' on familiar people (Semenza, 2009, p.356), but she performed well in similar tasks involving common nouns. Semenza, Zettin and Borgo, (1998), report a patient who was unable to retrieve information about a familiar person when confronted with a picture or a description of it. The patient, however, could recover all such information once he was provided with the name of the individual. Finally, Semenza, Sartori and D'Andrea, (2003) report a patient who was unable to name familiar faces. When shown pictures of familiar people, the patient could give accurate descriptions of them but could not retrieve the name. He was able, however, to recognize a face if he was given the name.

There is also evidence on selective sparing of names. Van Lancker (1990) and Semenza and Sgaramella (1993) report patients who were able to recall the relevant names when presented with corresponding faces, but did not retrieve any associated descriptive information. See also Pavão Martins and Farrajota, 2007; Lyons, Hanley and Kay, 2002; McKenna and Warrington, 1978; and Schmidt, Buchanan and Semenza, 2004.

Second, there is empirical evidence on the unique difficulty of proper name retrieval. Everyone has, at some point, been unable to recall someone's name while knowing who that person was and how she was named. Folk psychology describes this as the tip-of-the-tongue or тот phenomenon. Cohen (1990) shows that recalling proper names is just as difficult as recalling meaningless, non-word expressions (e.g. 'blick') and argues that the тот phenomenon is owed to a lack of semantic associations for proper names. McWeeny, Young, Hay and Ellis (1987) found that it is easier to associate faces with professions (e.g. a baker) than 
with proper names (e.g. Mr. Baker). Names are more difficult to retrieve than common nouns even if there is no difference in 'phonological form or frequency of occurrence' (Semenza, 2009, p. 366). Even with healthy patients, repeating supra-span lists of words shows 'a significantly weaker primacy effect if the list is composed of proper names rather than if it is composed of common names' (ibid.). ${ }^{9}$ Finally, Pelamatti, Pascotto and Semenza (2003) suggest that name retrieval is much more demanding in terms of brain metabolism than common noun retrieval. They found that both altitude and aging decreased primacy effects.

As Semenza (2009) forcefully argues, this evidence suggests that unlike common nouns, 'proper names denote individuals, but do not essentially rely on, or rely on only to a limited extent, sets of attributes' (ibid., p. 350). Several access models of memory have been offered to account for these data (see Cohen and Burke, 1993; Valentine, Brennen and Brédart, 1996). Pretty much all the models propose a single connection between the referent and the name, while they describe multiple connections between the 'components of the concept' and the common noun. As a result, access to descriptive information about the referent is not necessary to process the relevant proper names. If it were necessary, there would be more entry points within memory from which to access a name. Proper names would not be difficult to retrieve. Memory-wise, proper names are expensive while common nouns, and with them, definite descriptions, are cheap because the former carry so little information (see Table 3).

This suggests, against semantic and dual description theories, that proper names do not have any descriptive content; or, alternatively, that definite descriptions do not define proper names. Could descriptions define names without necessarily being part of name processing? Is it enough for semantic purposes that descriptions be weakly associated with names? We doubt that this would be enough to satisfy the description theorist's claim that descriptions are the content of names. But even if

Memory for Proper Names

Description Theories

(1) Name retrieval is difficult: TOT problems, anomia, and weak primacy.

(2) Name retrieval does not require access to descriptive information.

(3) Names carry very minimal information about the referent.
(1) Retrieving $N$ is just like retrieving $D D$.

(2) Retrieving $N$ requires retrieving unique descriptive information.

(3) $N$ carries unique, descriptive information.

Table 3 Actual memory and Descriptivist demands for names.

9 In general people's short-term memory is limited to recalling approximately seven items of a list (e.g. words, numbers). Supra-span lists are longer than this short-term memory capacity (e.g. they include twelve words). The first items (primacy effect) and last items (recency effect) tend to be better preserved. The primacy effect is commonly attributed to the fact that those items are already stored in long-term memory, while the recency effect is attributed to short-term memory (see Semenza, 2009). 
it were so, the evidence reviewed shows successful name processing without any (not even weakly) associated descriptions (see Van Lancker, 1990; Semenza and Sgaramella, 1993). Understanding a proper name does not seem to be the same as understanding some or other definite description.

\section{Preliminary Conclusions}

We have argued (see Section 2) that description theories, whether referential, semantic, or dual, are committed to the claim that processing names requires understanding (or processing) uniquely identifying properties, either for reference fixing (COgnitive), meaning determination (Memory), or both. In Section 3 we presented empirical evidence suggesting that COGNITIVE and MEMORY are unsupported. Description theories lack a proper empirical standing.

We have made a case, on developmental grounds, against COGNITIVE. Proper names are among the first words in an infant's lexicon. Some minimal understanding of reference is, of course, needed for this to be the case, possibly founded in prelinguistic knowledge or natural preparedness. ${ }^{10}$ If uniquely identifying concepts were required for reference fixing, then an understanding of them should also appear as early as 6 months. However, there is no evidence of uniquely identifying property concepts developing that early; an understanding of even general properties is found about 9 months and develops slowly. This undermines the empirical standing of description theories. Subjects do not fix the reference of names by means of definite descriptions.

The same evidence appears to undermine MEMORY. It is plausible (see 3.1) to think that 6-month-olds have an adequate understanding of their own names qua singular terms that refer to themselves. Yet (see 3.2) it seems clear that 6-montholds cannot understand uniquely identifying properties of the sort denoted by a definite description. Infants do not understand names in terms of definite descriptions. Unlike what the MEMORY analogue of description theories predicts, definite descriptions are not part of the 'contents' they process when understanding names.

We also made a case on neuropsychological grounds against MEMORY. Proper names are very costly memory-wise, suggesting that they lack any descriptive content. Their acquisition and production does not require access to descriptive information about the referent. Names and descriptions appear to be different for the human mind. Storing and retrieving a name is not tantamount to storing and retrieving a definite description. ${ }^{11}$

10 Regarding the prelinguistic understanding of reference see Hall, 2002. See Wellman and Gelman, 1997 and Gelman, 1990 on distinctions such as the person/non-person and animate/inanimate. Even psychologists who generally disavow unlearned principles recognize the need for some preparedness. See, for example, Rakison and Lupyan, 2008.

11 There is one more theory of names that, we believe, is undermined by the data, whether or not it counts as a description theory. Owed to Burge (1973), this theory claims that proper 


\section{Objections and Replies}

In this section we defend our claims by showing their philosophical relevance. First, we argue that philosophical theories of language are concerned with actual language use. Second, we argue against alternative explanations of the data by showing why the evidence concerns competent understanding of names. Third, we offer a distinct preliminary alternative account of reference from a developmental perspective. Finally, we address whether psychological evidence is of any philosophical interest.

\subsection{Accounting for Natural Languages}

There is agreement on the claim that actual language use is relevant qua explanandum. Description theorists, like Dummett claim this explicitly (see also Jackson, 1998a, p. 203; Stanley, 1997, p. 564; Kroon, 2004, pp. 4-5; and Lewis, 1975):

What we have to give is an account of what a person knows when he knows what a word or expression means, that is, when he understands it. [....] An account of understanding language, i.e. of what it is to know the meanings of words and expressions in the language, is thus at the same time an account of how language functions, that is, not only of how it does what it does, but of what it is that it does (Dummett, 1973, p. 92; see also Dummett, 1993).

Is language use also relevant qua explanans? Lewis (1992), Stalnaker (1999) and Kaplan (1989) seem to agree that: 'it is our use of language that somehow determines meaning' (Lewis, 1992, p.106). If this is so and linguistic competence is partly, as a matter of fact, knowledge of meaning, then language use becomes a source of explanation of linguistic competence. We agree with Schiffer (2003) and (2006) that a proper account of linguistic competence must include an account of 'the information processing that underlies, and thus accounts for, the person's ability to understand utterances in her language' (Schiffer, 2006, p. 281) — but see Lewis, 1992; Smith, 2007; and Matthews, 2006.

We believe, following Segal (2001), that 'it is very important that semantic theorizing not proceed in a vacuum. It proceeds best within a framework of assumptions about the nature of semantic facts that allows for some reasonably explicit methodology.' And we also agree that cognitive psychology provides such a framework allowing us to 'know what sorts of things count as evidence for or against specific semantic theories, and why they do so' (Segal, 2001, p. 548).

names are predicates (or common nouns); ' $\mathrm{N}$ ', for example, denotes the property of BEING NAMED ' $N$ '. On this view, a determiner follows singular uses of names; e.g. the logical structure of ' $\mathrm{N}$ is $\mathrm{F}$ ' is [[that $\mathrm{N}]$ is $\mathrm{F}]$. Both the developmental and memory evidence suggest that proper names are very distinct from common nouns (see Semenza, Longobardi, Cocolo and Graná, 2001; Semenza, Graná, Cocolo, Longobardi and Di Benedetto, 2002). 
We recognize different ways of studying language use. The studies reviewed in Section 3 offer various approaches to pursue (see also Machery et al. 2004; Braisby, Franks and Hampton, 1996).

\subsection{Competence Descriptivism?}

It is reasonable to distinguish between what enables a speaker to understand a language and the way in which she actually produces and comprehends her utterances (see Smith, 2007, p. 962). Chomsky's competence/performance distinction has given place to a tradition that takes evidence of the latter sort to be irrelevant for the former. Can description theorists follow this strategy and explain away the counter evidence by taking it to be about performance? We think not.

First, recent work in psycholinguistics suggests that competence and performance are not as separate and independent as Chomsky's distinction suggests. 'If, for example, a language processor is constrained by limitations of human working memory, that processor itself may have an impact on the very nature of syntactic structure' (Shatz, 2007a, p. 6). See also Lewis and Vasishth, 2005; Diesendruck, 2007.

Second, the Chomskian analogy is about knowledge of language, not about cognitive abilities in general. Description theorists would have to claim, for example, that young infants do understand definite descriptions competently, but that there's no evidence of this because identifying descriptions requires performance skills that infants lack. Doing so, however, would leave all the evidence unexplained.

The data show that young infants have a poor ability to understand property concepts and representations. They seem to understand very few general ones (e.g. shape) and no uniquely identifying ones. If young infants competently understand definite descriptions, why are they so bad with properties? It seems far-fetched to claim that infants have a prelinguistic understanding of uniquely identifying concepts (see Gelman and Williams, 1998, for discussion). Neuropsychological research shows that processing proper names requires different functional, anatomic, and metabolic resources from those of common nouns (see Semenza, 2006). If in terms of competence, understanding proper names just is the same as understanding definite descriptions, why are there such stark differences?

Furthermore, the very fact that there is evidence of a double dissociation of proper names from common nouns in normal subjects is a problem for description theories. It is common to take double dissociations as evidence of distinct processing modules (see Shallice, 1988). Alternative connectionist explanations may avoid postulating modules (see Juola and Plunkett, 2000), but even these have to explain why healthy patients exhibit functional, anatomic, and metabolic differences between proper names and common nouns. It seems that one is forced to postulate (at least) different functions (as in Semenza, 2006 and 2009) within the same network. Either way, different modules or functions are incompatible with description theories. On the latter view, to understand a name just is to understand a definite description (see page 57). It is not as if there are two different functions performed by the same apparatus but, rather, more like there is just one performed for both name and 
description processing. And whatever function that may be, it will require accessing descriptive information for name processing, a demand that most agree is not met (see Brédart, Brennen, Delchambre, McNeill and Burton, 2005).

\subsection{If not Definite Descriptions, What Then?}

Descriptivists claim competent name understanding requires the use of definite descriptions. Why not say that the data are not about competent subjects? To reject this possibility we need an alternative account of name competence that is consistent with the evidence. We sketch the sort of story we support.

On our view, the problem of reference fixing can be solved in terms of a natural preparedness of subjects to understand the reference relation. This view is importantly distinct from other non-descriptivist accounts, such as La Palme Reyes, Macnamara, Reyes and Zolfaghari (1993). First, unlike La Palme Reyes and colleagues, we do not think that common nouns play a necessary role. An understanding of common nouns starts to appear later (12-18 months) than an understanding of names (6 months). Second, we do not claim that an understanding of reference per se must be innate. We take our claim for a natural preparedness to be easier to support. All that our argument needs is the existence of a prelinguistic ability to understand reference, along with an inability to understand definite descriptions. There is evidence for both claims.

On the one hand, there is independent evidence suggesting that reference is unlearned, independent of perceptual characteristics, universal across languages, and primitive for all of them (see Hall, 1999). Most importantly, understanding reference seems to require some uniquely human cognitive abilities. In a recent review of the literature in comparative psychology, Penn, Holyoak and Povinelli (2008) argue for a distinctively human cognitive capacity: The ability to interpret the environment symbolically, by using higher-order, abstract, relations. If their claim is correct, then this uniquely human, cognitive endowment is good enough to account for the natural preparedness of humans to understand and use names. All that humans need to do is identify a pair of physical objects (e.g. a unique sequence of sounds and an entity) and take one to stand for, or point to the other. Recent research (see Hall, 2009; Jeshion, 2009) shows that proper names are given to individually salient objects. Not surprisingly, most of these are persons. Other studies also show that young children reason differently about people and inanimate objects (see Bonatti, Frott, Zangl and Mehler, 2002; Kuhlmeier, Bloom and Wynn, 2004; Rakisson and Poulin-Dubois, 2001). This, together with Spelke and colleagues' (1992) finding that a notion of BOUNDED PHYSICAL OBJECT is not acquired through experience, gives us the ingredients we need.

On the other hand, the evidence suggests that understanding properties, and with them, common nouns, is not prelinguistic. Even more, the evidence suggests that proper names and common nouns develop separately, with nouns appearing much later than names (see Booth and Waxman, 2009). Not surprisingly, there 
are traces of this in adulthood, as the evidence from memory on proper names suggests. The relevant subjects presented all through Section 3 seem to understand names competently without any need of definite descriptions. There is evidence suggesting that those subjects have everything they need to understand reference, thanks to their human cognitive endowment. Indeed human infants as young as 6 months demonstrate the integration of the needed components. The descriptivist account of name competence is mistaken.

\subsection{Why Philosophers Should Care}

Frege (1917) seemed to think that philosophy had nothing, or little, to learn from psychology. Philosophical theories were meant to be logical, not psychological. But things have changed since. Goldman (1993) describes this shift very well: '[W]hile René Descartes and David Hume created their own theories of the mind, contemporary philosophers must give respectful attention to the findings of scientific research' (p. xii).

The recent history is replete with interactions between philosophy and the cognitive sciences. Goldman (1993) and Stich (1994) report many philosophical applications of cognitive science (see Chomsky, 1966; Spelke et al., 1992). Philosophy of language, and the theory of reference in particular, is no exception. Segal (2001) uses the same sort of evidence we do to compare the virtues of two different philosophical theories of names. Machery et al. (2004) argue that empirical data undermine the underlying methodology of traditional theorizing about names. ${ }^{12}$ Braisby et al. (1996) use empirical evidence on language use to argue against the essentialist theory of reference for kind terms (as in Kripke, 1980, and Putnam, 1975). (It is worth saying that our view on proper names is not meant to be extended to common nouns and, hence, kind terms.) More recent work makes use of empirical evidence for philosophical theorizing about proper names (see Jeshion, 2009; Coates, 2009).

We follow these theorists in applying the psychological evidence for philosophical purposes, in particular to address the problem of reference for proper names.

12 Note that our argument is different from theirs and rests on different data. They argue that, if a correct theory of reference were to 'use intuitions about reference to develop an empirically adequate account of the implicit theory that underlies ordinary use of names', then the evidence suggests that such a theory 'works in different ways in different dialects of the same language' (B.9). We doubt that speaker intuitions will provide an empirically adequate account of the actual psychological processes involved in name use. Our argument for such a theory is different. Moreover, there are problems with the experimental work and the interpretation they offer. For example, differences between Westerners and Easterners on their judgment task are not consistent, either within groups (high SDs) or across tasks. Also, Westerners are likely monolingual and Easterners are more likely not, and the variable of multilingualism influences performance on many tasks. See Deutsch, 2009 and Martí, 2009 for more discussion. 


\section{Concluding Remarks: Where Are We Now?}

We have argued that a subject can competently understand a name even if she lacks the cognitive skills that description theorists say she should have. We proposed natural preparedness as an alternative account and pointed to recent studies that give further support to this view (see also Valentine and Darling, 2006; Hollis and Valentine, 2001). Still, there are some open questions for both the psychology and philosophy of proper names.

\subsection{Psychology}

There is an interesting question as to whether nonhuman animals can understand proper names. It seems uncontroversial, for example, that dogs, and perhaps also other animals, respond to their own names. It would be surprising, however, if dogs could understand higher order abstract relations like reference. How do we account for the apparent similarity between infants and other animals on name recognition?

First, there are good reasons to think that language use is a uniquely human ability. Shatz $(1994,2007 b)$ presents evidence that even toddlers use language in a way that shows an understanding of higher order, relational, abstract reasoning, and even Theory of Mind abilities such as understanding false belief. Penn and colleagues' (2008) forceful argument supports this view. They offer much evidence on behalf of the distinctiveness of the human mind, encompassing different areas of human cognition including language, Theory of Mind, logic, and causal thinking. They propose that humans are able to 'reinterpret the world in a symbolic-relational fashion' by understanding higher-order, abstract relations. This cognitive capacity 'evolved in only one lineage - ours. Nonhuman animals didn't (and still don't) get it' (Penn et al., 2008, p. 129).

Second, the very feature that makes language a uniquely human ability makes the preparedness account plausible. Understanding reference requires an understanding of higher-order abstract relations, e.g. understanding that 'Jon' refers to Jon. Others have argued that more advanced uses of proper names (e.g. identity statements) require an understanding of higher-order relations as well (Perner, Rendl and Garnham, 2007). Thus, even if infants seem to be like dogs in their early understanding of names, given that they, and only they, progress beyond that raises the question of whether there are no underlying differences between infants and dogs from the very beginning. So, what do nonhuman animals understand when they identify their names?

Penn and colleagues (2008) have an answer here. According to them, even though there is functional discontinuity between humans and nonhuman animals, there is still no unexplainable gap in between: '. . different species, as well as different modules within the cognitive architecture of a given species, approximate different features of a PSS [Physical Symbol System] to varying degrees' (Penn et al. 2008, p. 128). It may be that nonhuman use of names differs by not requiring 
higher-order relations, but yet approximates enough to be regarded as some kind of comprehension of names (see Shatz, 2008). ${ }^{13}$

\subsection{Philosophy}

There are several philosophical controversies surrounding proper names. There is a dispute about their use within propositional attitude ascriptions (e.g. 'S believes that. .'), as well as within modal contexts (e.g. 'it is necessary that...'). And there is also a debate with respect to the use of empty names in general (e.g. 'Pegasus is a horse') as well as within negative existential constructions (e.g. 'Pegasus does not exist'). We cannot address all the relevant literature. A variety of work from both philosophers and psychologists is relevant here: See Frege, 1892; Russell, 1905; Jackson, 1998; Kroon, 2004; Kripke, 1980; Stalnaker, 1999; Soames , 2002; Reimer, 2003; Lycan, 2006; Everett and Hofweber, 2000; Leslie, 1987; Lillard, 2002; and Nichols and Stich, 2000 among others.

Also, while this paper makes a contribution to the philosophical debate on reference for proper names, the alternative account we sketch is just one among various non-descriptivist theories (see, for example, Devitt, 1981, and Evans, 1982). We do not offer an adequate discussion of such theories. Doing so is desirable, but beyond the scope of this paper.

\subsection{Conclusions}

Our claim is still standing. Description theories are ill equipped as theories of what competent subjects understand when using proper names. We have offered considerable evidence against the claim that learning how to use a proper name requires an understanding of uniquely identifying properties or that names carry uniquely identifying information about their referents. Description theories fail both as theories of reference and theories of meaning for proper names in natural languages.

Instituto de Investigaciones Filosóficas Universidad Nacional Autonoma de México Ciudad Universitaria, México

Department of Psychology Department of Linguistics University of Michigan, Ann Arbor

13 Our account of reference in terms of prelinguistic understanding requires some early symbolic understanding from the child. An anonymous reviewer noted that autistic children have problems with certain kinds of symbolic understanding, but seem to have no problems understanding names. However, some patients with Asperger's Syndrome (mild autistic spectrum disorder) do well in tasks involving complex forms of symbolic understanding. This opens up another area for future discussion: The extent to which autism affects symbolic understanding. 


\section{References}

Austin, J. L. 1962: How to Do Things with Words. Oxford: Oxford University Press.

Bach, K. 1981: What's in a name. Australasian Journal of Philosophy, 59, 371-86.

Bonatti, L., Frott, E., Zangl, R. and Mehler, J. 2002: The human first hypothesis: identification of conspecifics and object individuation in the young infant. Cognitive Psychology, 44, 388-26.

Booth A. E. and Waxman, S. R. 2009: A horse of a different color: specifying with precision infants' mapping of novel nouns and adjectives. Child Development, 80, $15-22$.

Bower, T. G. 1974: Development in Infancy. San Francisco: W.H. Freeman.

Braisby, N., Franks, B. and Hampton, J. 1996: Essentialism, word use, and concepts. Cognition, 59, 247-74.

Braun, D. 2007: Names and natural kind terms. In E. Lepore and B. C. Smith (eds), Handbook of Philosophy of Language. Oxford: Oxford University Press.

Brédart, S., Brennen T., Delchambre, M., McNeill, A. and Burton, A. M. 2005: Naming very familiar people: when retrieving names is faster than retrieving semantic biographical information. British Journal of Psychology, 96, 2, 205-14.

Burge, T. 1973: Reference and proper names. Journal of Philosophy, 70, 14, 425-39.

Chomsky, N. 1966: Cartesian Linguistics. New York: Harper \& Row.

Choi, S. and Gopnik, A. 1993: Nouns are not always learned before verbs: an early verb spurt in Korean. In E. V. Clark (ed.), The Proceedings of the 25th annual Child Language Research Forum. New York: Cambridge University Press.

Coates, R. 2009: A strictly Millian approach to the definition of the proper name. Mind E Language, 24, 4, 435-46.

Cohen, G. 1990: Why is it difficult to put names to faces? British Journal of Psychology 81, 287-97.

Cohen, G. and Burke, D. M. 1993: Memory for proper names: a review. Memory, 1, 249-63.

Deutsch, M. 2009: Experimental philosophy and the theory of reference. Mind $\mathcal{E}$ Language, 24, 445-66.

Devitt, M. 1981: Designation. New York: Columbia University Press.

Diesendruck, G. 2007: Mechanisms of word learning. In E. Hoff and M. S. Shatz (eds), Handbook of Language Development. Oxford: Blackwell.

Dummett, M. 1973: Frege: Philosophy of Language. New York: Harper \& Row.

Dummett, M. 1981: The Interpretation of Frege's Philosophy. London: Duckworth.

Dummett, M. 1993: What do I know when I know a language. In M. Dummett, Seas of Language. Oxford: Oxford University Press.

Evans, G. 1973: The causal theory of names. Proceedings of the Aristotelian Society. Supplementary Volume, 47, 187-208.

Evans, G. 1982: The Varieties of Reference. Oxford: Oxford University Press. 
Everett, A. and Hofweber, T. (eds) 2000: Empty Names, Fiction, and the Puzzles of Nonexistence. Stanford, CA: CSLI Publications.

Fodor, J. 1987: Psychosemantics: The Problem of Meaning in the Philosophy of Mind. Cambridge, MA: MIT Press.

Frege, G. 1892 [2001]: On sense and nominatum. In A. P. Martinich (ed.), The Philosophy of Language, 4th edn. Oxford: Oxford University Press.

Frege, G. 1917 [1997]: The thought. In M. Beaney (ed.), The Frege Reader. Oxford: Blackwell.

Gelman, R. 1990: First principles organize attention to and learning about relevant data: number and the animate-inanimate distinction as examples. Cognitive Science, 14, 79-106.

Gelman, R. and Williams, E. M. 1998: Enabling constraints for cognitive development and learning: domain specificity and epigenesis. In D. Kuhn and R. S. Siegler (vol. eds), Cognition Perception and Language, Vol. 2, in W. Damon (ed.), Handbook of Child Psychology. New York: Wiley, 5th edn.

Gentner, D. 1982: Why nouns are learned before verbs: Linguistic relativity versus natural partitioning. In S. A. Kuczaj (ed.), 1982: Language Development: Syntax and Semantics. Hillsdale, NJ: Lawrence Erlbaum.

Geurts, B. 1997: Good news about the description theory of names. Journal of Semantics, 14, 319-48.

Goldman, A. I. 1993: Philosophical Applications of Cognitive Science. Boulder, CO: Westview Press.

Hall, D. G. 1999 [2002]: Semantics and the acquisition of proper names. In R. Jackendoff, P. Bloom and K. Wynn (eds), Language, Logic and Concepts. Cambridge, MA: MIT Press.

Hall, D. G. 2009: Proper names in early word learning: Rethinking a theoretical account of lexical development. Mind \& Language, 24, 406-34.

Hallé, P. and Boysson-Bardies, B. D. 1996: The format of representation of recognized words in infants' early lexicon. Infant Behavior \& Development, 19, 463-81.

Hollis, J. and Valentine, T. 2001: Proper-name processing: are proper names pure referencing expressions? Journal of Experimental Psychology 27, 99-116.

Jackson, F. 1998: Reference and description revisited. Philosophical Perspectives, 12, 201-18.

Jeshion, R. 2009: The significance of names. Mind \& Language, 24, 372-405.

Juola, P. and Plunkett, K. 2000: Why double dissociations don't mean much. In G. Cohen, R. A. Johnston and K. Plunkett (eds), Exploring Cognition: Damaged Brains and Neural Networks: Readings in Cognitive Neuropsychology and Connectionist Modelling. Hove: Psychology Press.

Jusczyk, P. W. and Aslin, R. N. 1995: Infants' detection of sound patterns of words in fluent speech. Cognitive Psychology, 29, 1-23. 
Jusczyk, P. W. and Mandel-Emer, D. 1997: What's in a name? How infants respond to some familiar sound patterns. http://hincapie.psych.purdue.edu /Jusczyk/pdf/ Name.pdf.

Kaplan, D. 1989: Demonstratives. An essay on the semantics, logic, metaphysics, and epistemology of demonstratives and other indexicals. In J. Almog, J. Perry and H. Wettstein (eds), Themes from Kaplan. Oxford: Oxford University Press.

Kripke, S. 1980: Naming and Necessity. Cambridge, MA: Harvard University Press.

Kroon, F. 2004: Descriptivism, pretense, and the Frege-Russell problems. Philosophical Review, 113, 1, 1-30.

Kuhlmeier, V., Bloom, P. and Wynn, K. 2004: Do 5-month-olds see humans as material objects? Cognition, 94, 95-101.

La Palme Reyes, M., Macnamara, J., Reyes, G. E. and Zolfaghari, H. 1993: Proper names and how they are learned. Memory 1, 4, 433-55.

Leslie, A. M. 1987: Pretense and representation: the origins of 'theory of mind'. Psychological Review, 94, 412-26.

Lewis, D. 1975 [1983]: Languages and language. In D. Lewis, Philosophical Papers, Vol. 1. Oxford: Oxford University Press.

Lewis, D. 1984: Putnam's paradox. Australasian Journal of Philosophy, 62, 1-17.

Lewis, D. 1992: Meaning without use: reply to Hawthorne. Australasian Journal of Philosophy, 70, 106-10.

Lewis, R. and Vasishth, S. 2005: An activation-based model of sentence processing as skilled memory retrieval. Cognitive Science, 29, 375-419.

Lillard, A. S. 2002: Just through the looking glass: children's understanding of pretense. In R. W. Mitchell (ed.), Pretending and Imagination in Animals and Children. Cambridge: Cambridge University Press.

Lucchelli, F. and Renzi, E. 1992: Proper name anomia. Cortex, 28, 221-30.

Lycan, W. 2006: Names. In M. Devitt and R. Hanley (eds), The Blackwell Guide to the Philosophy of Language. Oxford: Blackwell.

Lyons, F., Hanley, J. R. and Kay, J. 2002: Anomia for common names and geographical names with preserved retrieval of names of people: a semantic memory disorder. Cortex, 38, 23-35.

Machery, E., Mallon, R., Nichols, S. and Stich, S. 2004: Semantics, cross-cultural style. Cognition, 92, B1-B12.

McKenna, P. and Warrington, E. K. 1978: Category specific naming preservation: a single case study. Journal of Neurology, Neurosurgery and Psychiatry, 41, 571-74.

McWeeny, K. H., Young, A., Hay, D. C. and Ellis, A. W. 1987: Putting names to faces. British Journal of Psychology, 78, 143-44.

Mandel, D. R., Jusczyk, P. W. and Pisoni, D. B. 1995: Infants' recognition of the sound patterns of their own names. Psychological Science 6, 315-18.

Margolis, E. and Laurence, S. 1999: Concepts and cognitive science. In E. Margolis and S. Laurence (eds), Concepts. Core Readings. Cambridge, MA: MIT Press.

(C) 2011 Blackwell Publishing Ltd 
Martí, G. 2009: Against semantic multi-culturalism. Analysis, 69, 1, 42-48.

Matthews, R. J. 2006: Knowledge of language and linguistic competence. Philosophical Issues: Philosophy of Language, 16, 200-20.

Matushansky, O. 2008: On the linguistic complexity of proper names. Linguistics and Philosophy, 21, 573-627.

Miceli, G., Capasso, R., Daniele, A., Esposito, T., Magarelli, M. and Tomaiuolo, F. 2000: Selective deficit for people names following left temporal damage: an impairment of domain specific conceptual knowledge. Cognitive Neuropsychology, 17, 489-516.

Mill, J. S. 1864: A System of Logic. New York: Harper and Brothers.

Nelson, K. 1973: Structure and strategy in learning to talk. Monographs of the Society for Research in Child Development, 38, 1-135.

Nelson, K. 1974: Concept, word, and sentence: interrelations in acquisition and development. Psychological Review, 81, 267-85.

Nichols, S. and Stich, S. 2000: A cognitive theory of pretense. Cognition, 74, 115-47.

Pavão Martins, I. P. and Farrajota, L. 2007: Proper and common names: a double dissociation. Neuropsychologia, 45, 1744-56.

Pelamatti, G., Pascotto, M. and Semenza, C. 2003: Verbal free recall in high altitude: proper names vs. common names. Cortex, 39, 97-103.

Penn, D. C., Holyoak, K. J. and Povinelli, D. J. 2008: Darwin's mistake: explaining the discontinuity between human and nonhuman minds. Behavioral and Brain Sciences, 31, 109-178. Cambridge: Cambridge University Press.

Perner, J., Rendl, B. and Garnham, A. 2007: Objects of desire, thought, and reality: problems of anchoring discourse referents in development. Mind E Language, 22, 475-513.

Plantinga, A. 1978: The Boethian Compromise. American Philosophical Quarterly, 15, 129-38.

Putnam, H. 1975: The meaning of 'meaning'. In H. Putnam, Mind, Language, and Reality, Vol. 2, Philosophical Papers. Cambridge: Cambridge University Press.

Rakison, D. and Poulin-Dubois, D. 2001: Developmental origin of the animateinanimate distinction. Psychological Bulletin, 127, 209-28.

Rakison, D. H. and Lupyan, G. 2008: Developing object concepts in infancy: an associative learning perspective. Monographs of the Society for Research in Child Development, 73, 1.

Reimer, M. 2003: Reference. In E. Zalta (ed.), Stanford Encyclopedia of Philosophy, http://plato.stanford.edu/entries/reference

Russell, B. 1905 [2001]: On denoting. In A. P. Martinich (ed.), The Philosophy of Language. Oxford: Oxford University Press.

Schiffer, S. 2003: Knowledge of meaning. In A. Barber (ed.), Epistemology of Language. Oxford: Oxford University Press. 
Schiffer, S. 2006: Two perspectives on knowledge of language. Philosophical Issues: Philosophy of Language, 16, 275-87.

Schmidt, D., Buchanan, L. and Semenza, C. 2004: Sparing of proper names and dates in aphasia. Brain and Language, 91, 9-10.

Searle, J. 1983: Intentionality. Cambridge: Cambridge University Press.

Segal, G. 2001: Two theories of names. Mind \& Language, 16, 547-63.

Semenza, C. 2006: Retrieval pathways for common and proper names. Cortex, 42, 884-91.

Semenza, C. 2009: The neuropsychology of proper names. Mind \& Language, 24, 349-71.

Semenza, C., Graná, A., Cocolo, R., Longobardi, G. and Di Benedetto, P. 2002: Proper names and noun-to-determiner movement in aphasia: a case study. Brain and Cognition, 48, 542-45.

Semenza, C., Longobardi, G., Cocolo, R. and Graná, A. 2001: Proper names and movement to determiner position: a neurolinguistic study on Alzheimer patients. Cortex, 37, 734-36.

Semenza, C., Sartori, G. and D'Andrea, J. 2003: He can tell which master craftsman blew a Venetian vase, but he cannot name the Pope: a patient with a selective difficulty in naming faces. Neuroscience Letters, 352, 73-75.

Semenza, C. and Sgaramella, T. M. 1993: Production of proper names: a clinical study of the effects of phonemic cueing. Memory, 1, 265-80.

Semenza, C. and Zettin, M. 1989: Evidence from aphasia for the role of proper names as pure referring expressions. Nature, 342, 678-79.

Semenza, C., Zettin, M. and Borgo, F. 1998: Names and identification: an access problem. Neurocase, 4, 45-53.

Shallice, T. 1988: From Neuropsychology to Mental Structure. Cambridge: Cambridge University Press.

Shatz, M. 1994: A Toddler's Life. New York: Oxford University Press.

Shatz, M. 2007a: On the development of the field of language development. In E. Hoff and M. Shatz, (eds), Handbook of Language Development. Oxford: Blackwell.

Shatz, M. 2007b: Revisiting A Toddler's Life for The Toddler Years: conversational participation as a tool for learning across knowledge domains. In C. A. Brownell and C. B. Kopp (eds), Socioemotional Development in the Toddler Years. New York: Guilford.

Shatz, M. 2008: Language as a consequence and an enabler of the exercise of higherorder relational capabilities: evidence from toddlers. Behavioral and Brain Sciences, 31, $145-46$.

Smith, B. C. 2007: What I know when I know a language. In E. Lepore and B. C. Smith (eds), The Oxford Handbook in the Philosophy of Language. Oxford: Oxford University Press. 
Smith, L. B. 1984: Young children's understanding of attributes and dimensions: a comparison of conceptual and linguistic measures. Child Development, 55, 363-80.

Snedeker, J. and Gleitman, L. 2004: Why is it hard to label our concepts? In G. Hall and S. Waxman (eds), Weaving a Lexicon. Cambridge, MA: MIT press.

Snedeker, J., Li, P. and Yuan, S. 2003: Cross-cultural differences in the input to early word learning. Proceedings of the 25th Annual Cognition Conference, available online at: http://www.wjh.harvard.edu/ lds/pdfs/snedeker-li-yuan.pdf

Soames, S. 2002: Beyond Rigidity. Oxford: Oxford University Press.

Spelke, E. S., Breinlinger, K., Macomber, J. and Jacobson, K. 1992: Origins of knowledge. Psychological Review, 19, 4, 603-32.

Stager, C. L. and Werker, J. F. 1997: Infants listen for more phonetic detail in speech perception than in word-learning tasks. Nature, 388, 381-82.

Stalnaker, R. 1999: Context and Content. Oxford: Oxford University Press.

Stanley, J. 1997: Names and rigid designation. In R. Hale and C. Wright (eds), $A$ Companion to the Philosophy of Language. Oxford: Blackwell.

Stich, S. 1994: Psychology and philosophy. In S. Guttenplan (ed.), A Companion to the Philosophy of Mind. Oxford: Blackwell.

Strawson, P. F. 1959: Individuals. London: Methuen.

Tardif, T., Shatz, M. and Naigles, L. 1997: Caregiver speech and children's use of nouns versus verbs: a comparison of English, Italian, and Mandarin. Journal of Child Language, 24, 535-65.

Tardif, T., Fletcher, P., Liang, W., Zhan, Z., Kaciroti, N. and Marchman, V. 2008: Baby's first ten words. Developmental Psychology, 44, 929-38.

Tincoff, R. and Jusczyk, P.W. 1999: Some beginnings of word comprehension in 6-month-olds. Psychological Science, 10, 172-75.

Valentine, T., Brennen, T. and Brédart, S. 1996: The Cognitive Psychology of Proper Names. London: Routledge.

Valentine, T. and Darling, S. 2006: Competitor effects in naming objects and famous faces. European Journal of Cognitive Psychology, 18, 686-707.

Van Lancker, D. 1990: Preserved recognition of familiar personal names in global aphasia. Brain and Language, 39, 511-29.

Wellman, H. M. and Gelman, S. A. 1997: Knowledge acquisition in foundational domains. In D. Kuhn and R. S. Siegler (eds), Cognition Perception and Language. Handbook of Child Psychology, 2. New York: Wiley.

Wittgenstein, L. 1953: Philosophical Investigations. London: MacMillan.

$\mathrm{Xu}, \mathrm{F}$. 2002: The role of language in acquiring object kind concepts in infancy. Cognition, 85, 223-50.

Xu, F. and Carey, S. 1996: Infants' metaphysics: the case of numerical identity. Cognitive Psychology, 30, 111-53.

Xu, F., Carey, S. and Quint, N. 2004: The emergence of kind-based object individuation in infancy. Cognitive Psychology, 49, 155-90. 